\title{
Decreased telomere length in children with cartilage-hair hypoplasia
}

\author{
Kostjukovits, Svetlana
}

2017-05

Kostjukovits, S, Degerman , S , Pekkinen, M , Klemetti , P , Landfors , M , Roos , G , Taskinen, M \& Makitie , O 2017 , ' Decreased telomere length in children with cartilage-hair hypoplasia ' , Journal of Medical Genetics , vol. 54 , no. 5 , pp. 365-370 . https://doi.org/10.1136/jmedgenet-2016-10

http://hdl.handle.net/10138/311364

https://doi.org/10.1136/jmedgenet-2016-104279

cc_by_nc

acceptedVersion

Downloaded from Helda, University of Helsinki institutional repository.

This is an electronic reprint of the original article.

This reprint may differ from the original in pagination and typographic detail.

Please cite the original version. 
3 Decreased telomere length in children with cartilage-hair hypoplasia.

4

5 Svetlana Kostjukovits, $\mathrm{MD}^{1,2}$, Sofie Degerman, $\mathrm{PhD}^{3}$; Minna Pekkinen, $\mathrm{PhD}^{2}$, Paula Klemetti, $\mathrm{MD}, \mathrm{PhD}^{1}$,

6 Mattias Landfors, $\mathrm{PhD}^{3}$, Göran Roos, $\mathrm{MD}, \mathrm{PhD}^{3}$; Mervi Taskinen, $\mathrm{MD}, \mathrm{PhD}^{1}$, Outi Mäkitie, $\mathrm{MD}, \mathrm{PhD}^{1,2,4, *}$.

81 Children's Hospital, University of Helsinki and Helsinki University Hospital, Helsinki, 00029, Finland

92 Folkhälsan Research Center, Helsinki, 00014, Finland

103 Department of Medical Biosciences, Pathology, Umeå University, Umeå, 901 85, Sweden

114 Center for Molecular Medicine, Karolinska Institutet and Clinical Genetics, Karolinska University

12 Hospital, Stockholm, SE-171 77, Sweden

13

$14 *$ Address all correspondence and requests for reprints to:

15 Outi Mäkitie, MD PhD

16 Folkhälsan Institute of Genetics

17 P.O.Box 63, FIN-00014 University of Helsinki, Helsinki, 00014, FINLAND

18 E-mail: outi.makitie@helsinki.fi

19 Tel. +358-9-191 25453, Fax. +358-9-191 25073

20

21 Word count: 2757. 
ABSTRACT

Background: Cartilage-hair hypoplasia $(\mathrm{CHH})$ is an autosomal recessive chondrodysplasia caused by $R M R P$ (RNA component of mitochondrial RNA processing endoribonuclease) gene mutations. Manifestations include short stature, variable immunodeficiency, anemia and increased risk of malignancies, all of which have been described also in telomere biology disorders. RMRP interacts with the telomerase reverse transcriptase (TERT) subunit, but the influence of $R M R P$ mutations on telomere length is unknown. We measured relative telomere length (RTL) in patients with $\mathrm{CHH}$, their first-degree relatives and healthy controls, and correlated RTL with clinical and laboratory features.

Methods: The study cohort included $48 \mathrm{CHH}$ patients with homozygous ( $\mathrm{n}=36)$ or compound heterozygous $R M R P$ mutations (median age 38.2 years, range 6.0-70.8 years), 86 relatives (74 with a heterozygous $R M R P$ mutation) and 94 unrelated healthy controls. We extracted DNA from peripheral blood, sequenced the $R M R P$ gene and measured RTL by quantitative-PCR.

Results: Compared with age- and sex-matched healthy controls, median RTL was significantly shorter in CHH patients ( $\mathrm{n}=40$ pairs, 1.05 vs $1.21, \mathrm{p}=0.017)$, but not in mutation carriers $(\mathrm{n}=48$ pairs, 1.16 vs 1.10 , $\mathrm{p}=0.224)$. RTL correlated significantly with age in $R M R P$ mutation carriers (rho $-0.482, \mathrm{p}<0.001$ ) and noncarriers (rho $-0.498, \mathrm{p}<0.001$ ), but not in patients (rho $-0.236, \mathrm{p}=0.107)$. Especially children ( $<18$ years) with CHH had shorter telomeres than controls (median RTL 1.12 vs 1.26, p=0.008). In patients with CHH, RTL showed no correlation with genotype, clinical or laboratory characteristics.

41 Conclusions: Telomere length was decreased in children with $\mathrm{CHH}$. We found no correlation between RTL and clinical or laboratory parameters.

\section{KEY WORDS}

Bone marrow failure, relative telomere length, $R M R P$, telomerase, telomere biology disorders. 
Telomeres constitute the protective end-parts of human chromosomes and can contribute to the pathogenesis of aging and cancer. The phenotype of inherited telomere disorders includes bone marrow failure, malignancies, pulmonary fibrosis, liver cirrhosis, diabetes, and cardiovascular and gastrointestinal diseases [1]. Telomeres shorten with every cell division, but the loss can be compensated by telomerasemediated elongation. The telomerase ribonucleoprotein complex consists of an RNA template, a catalytic reverse transcriptase subunit (TERT) and associated proteins that affect assembly, stability and recruitment of telomerase to telomeres (e.g. DKC, NOP10, NHP2, and GAR). In addition to telomere elongation, telomerase has also been associated with regulation of a number of cellular functions including survival, inflammation, apoptosis, transcription and metabolism [2]. Cartilage-hair hypoplasia (CHH, MIM \#250250) is a rare autosomal recessive metaphyseal chondrodysplasia caused by biallelic mutations in the RMRP (RNA component of mitochondrial RNA processing endoribonuclease) gene [3]. The disease is over-represented in the Amish and Finnish populations [4,5]. Clinical features include severe disproportionate short stature, hair hypoplasia, variable immunodeficiency, anemia and increased risk of malignancies. Genotype-phenotype correlations are inconsistent and clinical manifestations vary even between siblings [6]. Mutation carriers remain asymptomatic [5,7]. associated with cell proliferation and differentiation [8,9]. In addition, formation of a ribonucleoprotein with $\mathrm{CHH}$, e.g. growth retardation, bone marrow failure leading to anemia and immunodeficiency, and increased incidence of malignancies [11]. Pulmonary fibrosis has also been linked to TERT mutations, both in idiopathic cases and in patients with DC [12]. Interestingly, we have recently reported fibrosis-like changes on high-resolution computed tomography of the lungs in patients with $\mathrm{CHH}$ [13]. 
77 mutations have a significant impact on the telomere elongating functions of telomerase. In order to further

78 elucidate the pleiotropic consequences of RMRP mutations and the pathogenesis of CHH we evaluated

79 relative telomere lengths (RTL) in a large cohort of Finnish children and adults with CHH, their first-degree

80 relatives most of whom were heterozygous mutation carriers, and healthy controls. We also analyzed the

81 correlation of RTL with the patients' clinical and laboratory features.

82 


\section{METHODS}

Patients with genetically confirmed $\mathrm{CHH}$ were identified from the Finnish Chondrodysplasia

Register and recruited to a study exploring clinical, genetic and immunological characteristics of $\mathrm{CHH}$. Their first-degree relatives were contacted via the index persons. All individuals who agreed to participate, or their guardians, signed an informed consent. The study was approved by the Research Ethics Committee at Helsinki University Hospital, Finland.

Clinical and laboratory data were retrieved retrospectively from the patient hospital records, as well as prospectively during study visits. Apart from $\mathrm{CHH}$-related clinical features we evaluated also factors that could theoretically influence telomere length, such as smoking, obesity (body mass index Z-score) and hormone or immunosuppressive therapy. We also selected clinical features that could emerge from telomere impairment (immunodeficiency, malignancies, short stature), as well as the need for repeated blood transfusions and immunoglobulin replacement therapy. Since growth failure in $\mathrm{CHH}$ is progressive, we used age- and sex-specific growth data for $\mathrm{CHH}$ [14] to classify patients as having mild, moderate or severe growth failure, as described previously [15]. In the majority of patients, blood samples were drawn simultaneously for telomere measurement and for analysis of immunologic parameters characterizing the degree of bone marrow deficiency and/or immunodeficiency: hemoglobin, red blood cells, leukocytes, neutrophils, lymphocytes, CD3+, CD4+, CD8+, CD19+, CD16/56+ cell counts, immunoglobulin A, M and G levels, as well as Epstein-Barr virus (EBV) viral load and antibodies.

Control group. First-degree relatives of the patients $(n=86)$, all without features of $\mathrm{CHH}$, included 37 parents, 38 siblings and 11 children. Altogether, 74 of them were confirmed to be heterozygous $R M R P$ mutation carriers while 12 were negative for $R M R P$ mutations. The control group consisted of $R M R P$ mutation-negative individuals: 1$)$ siblings of the patients ( $\mathrm{n}=12)$ and 2$)$ individuals who had participated in our previous studies involving healthy children and adults $(\mathrm{n}=94)$. The data available on controls included age, sex, ethnic background (all of Finnish origin) and overall health (all healthy). Parts of the statistical analyses were performed in a case-control setting, and age- and sex-matched controls were selected from the control group for each patient or mutation carrier aiming at age difference of no more than 12 months. DNA extraction and RMRP sequencing. Peripheral blood samples were collected for all study participants. DNA was extracted with 5 Prime Archive Pure DNA Blood kit according manufacturer's 
instructions (5 Prime GmbH, Hilden; Germany). All samples were sequenced for RMRP to confirm the

113 genotype in patients with $\mathrm{CHH}$ and to confirm or exclude heterozygous mutations in the patients' unaffected

114 relatives and the healthy controls. For patients and their relatives, blood samples were collected

115 prospectively, whereas readily available DNA (extracted with the same methods) was used for healthy

116 controls. Primers for RMRP (GRCh37/hg19) were designed with Primer3 v.0.4.0

117 (http://frodo.wi.mit.edu/primer3/) for the gene, with a minimum of 60 bases of flanking regions adjacent to

118 the coding region. PCR amplification was performed with DreamTaq (ThermoScientific, Waltham, MA,

119 USA). The DNA fragments were then visualized with Midon Green Advanced DNA Stain (NIPPON

120 Genetics, GmbH, Europe) on a 1.2\% agarose gel, purified with ExoSAP (USB, Cleveland, OH, USA) and

121 labeled with BigDye Terminator v3.1 Cycle Sequencing kit (Applied Biosystems). After bidirectional

122 sequencing with an ABI3730 sequencer (Applied Biosystems), chromatograms were analyzed with

123 Sequencher v5.0 (Gene Codes Corporation, Ann Arbor, MI, USA) using genomic NG_017041.1 and RNA

124 reference sequence NR_003051.3. Primer sequences and detailed PCR protocols are available upon request.

125 Telomere length measurement. Telomere length was determined by the quantitative-PCR method

126 described by Cawthon [16], with minor modifications [17]. Briefly, sample DNA was analyzed in triplicate

127 wells in a separate Telomere (TEL) and a single copy gene (HBG) reaction on the ABI7900HT instrument

128 (Applied Biosystems), at two separate times. TEL/HBG (T/S) values were calculated by the $2^{-\Delta \mathrm{Ct}}$ method,

129 where $\Delta \mathrm{Ct}=$ average CtTEL-average CtHBG. RTL were generated by dividing samples $\mathrm{T} / \mathrm{S}$ value with the

$130 \mathrm{~T} / \mathrm{S}$ value of a reference CCRF-CEM cell line DNA included in all runs.

Statistical analysis. Subject's age on the day of blood sampling was used for the analyses. To evaluate RTL correlations, we classified individuals to categories of short, average or long RTL for age and used both, RTL itself and RTL category, in the analysis. These categories were determined based on RTL and age data from the healthy controls. Individuals with RTL > 0.5 standard deviation (SD) from the regression

135 line for age $v s$ RTL were classified as having long RTL, those with RTL $<-0.5$ SD as having short RTL, and 136 the remaining as having average RTL (Supplementary Figure 1). We applied the Mann-Whitney test for 137 categorical and the Spearman's coefficient (rho) for continuous variables. Linear or logistic regression 138 analysis was used for multivariate models. A p value $<0.05$ was considered significant. Statistical analyses 139 were performed with the IBM SPSS software. 


\section{RESULTS}

Patient characteristics. Altogether, 48 Finnish patients (31 females, 17 males) with $\mathrm{CHH}$

143 participated in the study. Their median age was 38.2 years (range 6.0-70.8 years). Sanger sequencing of the

$144 R M R P$ gene showed that most of the patients $(75 \%, 36 / 48)$ were homozygous for the g.70A $>\mathrm{G}$ mutation

145 (rs199476103, now referred to as g.71A>G) while 12 patients (25\%) were compound heterozygous for

146 g.70A $>$ G and either g.262G $>$ T mutation (rs727502774, now referred to as g.263G $>$ T) $(n=11)$ or a 10-

147 nucleotide duplication at position -13 (TACTCTGTGA, rs727502775) (n=1).

148 Tables 1 and 2 present patients' clinical and laboratory data. Nine patients had been diagnosed with

149 malignancies, including basal cell carcinoma $(n=6)$, B-cell lymphoma $(n=2)$, uterus carcinoma $(n=1)$ and

150 vocal cord carcinoma $(n=1)$. In the two patients who had survived lymphoma, no data were available on

151 EBV status in lymphoma samples. No EBV-associated diseases were reported in our patients. Blood EBV

152 viral load was undetectable by PCR in 10 individuals and 34/41 (83\%) patients tested positive for serum

153 antibodies to EBV. Two patients had required repeated red blood cell transfusions for anemia and another

154 four patients had been treated with immunoglobulin replacement therapy. Some individuals reported history

155 of smoking $(n=9)$, intake of inhaled corticosteroids for physician-diagnosed asthma $(n=15)$ or growth

156 hormone treatment in childhood $(n=3)$. 
Table 1. Clinical features of 47 study subjects with cartilage-hair hypoplasia.

\begin{tabular}{|c|c|c|}
\hline Clinical feature & Number of patients & Proportion of patients \\
\hline \multicolumn{3}{|l|}{ Growth deficiency } \\
\hline Severe & $3 / 47$ & $6 \%$ \\
\hline Moderate & $17 / 47$ & $36 \%$ \\
\hline Mild & $27 / 47$ & $58 \%$ \\
\hline \multicolumn{3}{|l|}{ History of } \\
\hline Pneumonia & $10 / 47$ & $19 \%$ \\
\hline Rhinosinusitis & $27 / 47$ & $57 \%$ \\
\hline Otitis media & $34 / 47$ & $72 \%$ \\
\hline Warts & $15 / 47$ & $32 \%$ \\
\hline Hospitalization for varicella & $5 / 34$ & $15 \%$ \\
\hline Smoking & 9/47 & $19 \%$ \\
\hline Normal susceptibility to infections* & $15 / 47$ & $32 \%$ \\
\hline Combined immunodeficiency** & $25 / 47$ & $53 \%$ \\
\hline \multicolumn{3}{|l|}{ History of } \\
\hline Malignancies & $9 / 47$ & $19 \%$ \\
\hline Repeated blood transfusions & $2 / 47$ & $4 \%$ \\
\hline Immunoglobulin therapy & $4 / 47$ & $8 \%$ \\
\hline Immunosuppressive therapy & $2 / 47$ & $4 \%$ \\
\hline Growth hormone treatment & $3 / 47$ & $6 \%$ \\
\hline Therapy with inhaled glucocorticoids & $15 / 47$ & $32 \%$ \\
\hline Bronchiectasis & $8 / 30$ & $27 \%$ \\
\hline Fibrosis-like lung changes & $5 / 30$ & $17 \%$ \\
\hline
\end{tabular}

* Normal susceptibility to infections was defined as occasional uncomplicated RTI or otitis media/rhinosinusitis not requiring surgical interventions, absence of pneumonias and sepsis and varicella not requiring hospitalization.

** Patients with warts, recurrent HSV infections, varicella requiring hospitalization or malignancy were considered to have combined immunodeficiency.

Table 2. Laboratory characteristics of study subjects with cartilage-hair hypoplasia. Cell counts are shown in cells $\times 10^{9} / 1$ with the exception of red blood cells $\left(\times 10^{12} / 1\right)$. Hemoglobin and immunoglobulin levels are in $\mathrm{g} / \mathrm{l}$. Normal values in adults represent local laboratory reference values.

\begin{tabular}{|l|l|l|l|l|}
\hline Laboratory parameter & $\begin{array}{l}\text { Normal } \\
\text { values in } \\
\text { adults }\end{array}$ & $\begin{array}{l}\text { Patients } \\
\text { tested (n) }\end{array}$ & $\begin{array}{l}\text { Results, median } \\
\text { (range) }\end{array}$ & $\begin{array}{l}\text { Patients with } \\
\text { decreased } \\
\text { counts/levels, n (\%) }\end{array}$ \\
\hline Red blood cells & $\begin{array}{l}\text { F 3.90-5.20, } \\
\text { M 4.25-5.70 }\end{array}$ & 47 & $4.32(2.69-5.34)$ & $5(11 \%)$ \\
\hline Hemoglobin & $\begin{array}{l}\text { F 117-155, } \\
\text { M 134-167 }\end{array}$ & 47 & $136(102-161)$ & $3(6 \%)$ \\
\hline White blood cells & $3.4-8.2$ & 47 & $6.0(1.2-12.0)$ & $4(9 \%)$ \\
\hline Absolute neutrophil count & $1.5-6.7$ & 47 & $1.76(0.28-8.40)$ & $3(6 \%)$ \\
\hline Absolute lymphocyte count & $1.3-3.6$ & 47 & $1.31(0.26-3.25)$ & $26(55 \%)$ \\
\hline CD3+ cells & $0.85-2.28$ & 46 & $0.93(0.16-3.01)$ & $19(41 \%)$ \\
\hline CD4+ cells & $0.458-1.406$ & 46 & $0.548(0.118-1.312)$ & $17(37 \%)$ \\
\hline CD8+ cells & $0.24-0.98$ & 46 & $0.30(0.04-1.72)$ & $19(41 \%)$ \\
\hline CD19+ cells & $0.12-0.43$ & 46 & $0.12(0.00-0.34)$ & $30(65 \%)$ \\
\hline CD16/56+ cells & $0.08-0.57$ & 46 & $0.18(0.05-0.55)$ & $3(7 \%)$ \\
\hline Immunoglobulin A & $0.52-4.84$ & 45 & $1.9(0.4-7.5)$ & $4(9 \%)$ \\
\hline Immunoglobulin M & $0.36-2.84$ & 46 & $0.9(0.2-3.1)$ & $4(9 \%)$ \\
\hline Immunoglobulin G & $6.8-15.0$ & 44 & $10.7(4.2-15.7)$ & $1(2 \%)$ \\
\hline
\end{tabular}

$\mathrm{F}$ females, $\mathrm{M}$ males, $\mathrm{n}$ number 
Telomere length. RTL measurement was performed by quantitative PCR on altogether 228 samples 175 from patients $(n=48)$, first-degree relatives $(n=86)$ and healthy unrelated controls $(n=94)$. Sanger sequencing 176 detected 74 carriers for RMRP mutations among the CHH patients' unaffected relatives (86\%). Table 3 177 demonstrates the characteristics of the participants according to the $R M R P$ mutation status. There was a 178 significant negative correlation between RTL and age in mutation carriers (rho -0.482, p<0.001) and non179 carriers (rho $-0.498, \mathrm{p}<0.001$ ), but not in patients (rho $-0.236, \mathrm{p}=0.107$ ) (Figure 1). RTL was not influenced 180 by sex in any age group. 
182 183 184

Table 3. Characteristics of patients with cartilage-hair hypoplasia, asymptomatic RMRP mutation carriers and non-carriers.

\begin{tabular}{|c|c|c|c|}
\hline & Patients with $\mathrm{CHH}$ & $R M R P$ mutation carriers & Mutation-negative individuals \\
\hline Size of group (n) & 48 & 74 & 106 \\
\hline Sex, F/M (\%) & $31 / 17(65 \% / 35 \%)$ & $39 / 35(53 \% / 47 \%)$ & $64 / 42(60 \% / 40 \%)$ \\
\hline Median age, years & $38.2(6.0-70.8)$ & $48.8(5.0-70.8)$ & $37.1(6.0-70.8)$ \\
\hline \multicolumn{4}{|l|}{ Number of subjects aged: } \\
\hline 5.0-18.0 years & $9(19 \%)$ & $17(23 \%)$ & $19(18 \%)$ \\
\hline 18.1-40.0 years & $17(35 \%)$ & $12(16 \%)$ & $40(38 \%)$ \\
\hline 40.1-70.8 years & $22(46 \%)$ & $45(61 \%)$ & $47(44 \%)$ \\
\hline Mutation type (n, \%): & & & $\mathrm{n} / \mathrm{a}$ \\
\hline homozygote, g.70A>G & $36(75 \%)$ & none & \\
\hline compound heterozygote & $12(25 \%)$ & none & \\
\hline heterozygote, g.70>G & none & $58(78 \%)$ & \\
\hline heterozygote, other* & none & $16(22 \%)$ & \\
\hline Relation to patients $(\mathbf{n}, \%)$ : & $\mathrm{n} / \mathrm{a}$ & & \\
\hline parents & & $37(50 \%)$ & none \\
\hline siblings & & $26(35 \%)$ & $12(11 \%)$ \\
\hline children & & $11(15 \%)$ & none \\
\hline unrelated & & none & $94(89 \%)$ \\
\hline
\end{tabular}

CHH cartilage-hair hypoplasia, F female, $\mathrm{M}$ male, n number of subjects, n/a not applicable, $R M R P$ RNA component of mitochondrial RNA processing endoribonuclease

* other mutations included g.262G $>$ T or a 10-nucleotide duplication at position -13 (TACTCTGTGA).

RTL in patients and mutation carriers. The proportion of CHH patients with short RTL for age was significantly higher $(52 \%, 25 / 48)$ than among mutation carriers $(20 \%, 15 / 74, \mathrm{p}<0.001)$ or healthy noncarriers $(29 \%, 31 / 106, \mathrm{p}=0.011)$ (Table 4). In the sub-analysis by age group, almost all children with CHH had short telomeres for age $(89 \%, 8 / 9)$. Further, two thirds of patients aged $18.1-40.0$ years $(65 \%, 11 / 17)$ and one fourth of those aged over 40.1 years $(27 \%, 6 / 22)$ had short telomeres. Compared with RMRP mutationnegative individuals, the proportion of patients with short RTL was significantly higher in children $(\mathrm{p}=0.016)$ and adults up to 40.0 years of age $(\mathrm{p}=0.047)$, but not in older individuals $(\mathrm{p}=0.769)$ (Table 4). 
Table 4. Relative telomere length as median (range) and as short, average or long for age in various age groups of patients with cartilage-hair hypoplasia, $R M R P$ mutation carriers and non-carriers. Higher proportion of patients demonstrated RTL short for age (bold) compared with mutation carriers $(\mathrm{p}<0.001)$ or healthy non-carriers $(\mathrm{p}=0.011)$. Compared with $R M R P$ mutation-negative individuals, the proportion of patients with short RTL was significantly higher in children $(\mathrm{p}=0.016)$ and adults up to 40.0 years of age $(\mathrm{p}=0.047)$, but not in older individuals $(\mathrm{p}=0.769)$.

\begin{tabular}{|c|c|c|c|c|c|c|}
\hline $\begin{array}{l}\text { Study } \\
\text { group }\end{array}$ & $\begin{array}{l}\text { Age group } \\
\text { (years) }\end{array}$ & $\begin{array}{l}\text { Number of } \\
\text { subjects }\end{array}$ & $\begin{array}{l}\text { Median RTL } \\
\text { (range) }\end{array}$ & $\begin{array}{l}\text { Subjects with } \\
\text { short RTL, n (\%) }\end{array}$ & $\begin{array}{l}\text { Subjects with } \\
\text { average RTL, n (\%) }\end{array}$ & $\begin{array}{l}\text { Subjects with } \\
\text { long RTL, n (\%) }\end{array}$ \\
\hline \multirow[t]{4}{*}{ Patients } & All ages & 48 & $1.07(0.70-1.81)$ & $25(52 \%)$ & $11(23 \%)$ & $12(25 \%)$ \\
\hline & $6.0-18.0$ & 9 & $1.12(0.88-1.31)$ & $8(89 \%)$ & $1(11 \%)$ & $0(0 \%)$ \\
\hline & $18.1-40.0$ & 17 & $1.08(0.91-1.72)$ & $11(65 \%)$ & $2(11.5 \%)$ & $4(23.5 \%)$ \\
\hline & $40.1-70.8$ & 22 & $1.06(0.70-1.81)$ & $6(27 \%)$ & $8(36.5 \%)$ & $8(36.5 \%)$ \\
\hline \multirow{4}{*}{$\begin{array}{l}\text { RMRP } \\
\text { mutation } \\
\text { carriers }\end{array}$} & All ages & 74 & $1.16(0.88-1.78)$ & $15(20 \%)$ & $32(43 \%)$ & $27(37 \%)$ \\
\hline & $5.0-18.0$ & 17 & $1.30(0.95-1.77)$ & $7(41 \%)$ & $6(35 \%)$ & $4(24 \%)$ \\
\hline & $18.1-40.0$ & 12 & $1.20(0.99-1.78)$ & $3(25 \%)$ & $5(42 \%)$ & $4(33 \%)$ \\
\hline & $40.1-70.8$ & 45 & $1.09(0.88-1.45)$ & $5(11 \%)$ & $21(47 \%)$ & $19(42 \%)$ \\
\hline \multirow{4}{*}{$\begin{array}{l}\text { RMRP } \\
\text { mutation- } \\
\text { negative } \\
\text { subjects }\end{array}$} & All ages & 106 & $1.16(0.71-2.05)$ & $31(29 \%)$ & $45(43 \%)$ & $30(28 \%)$ \\
\hline & $6.0-18.0$ & 19 & $1.25(0.86-2.05)$ & $7(37 \%)$ & $5(26 \%)$ & $7(37 \%)$ \\
\hline & $18.1-40.0$ & 40 & $1.22(0.88-1.78)$ & $14(35 \%)$ & $17(43 \%)$ & $9(22 \%)$ \\
\hline & $40.1-70.8$ & 47 & $1.07(0.71-1.45)$ & $11(23 \%)$ & $22(47 \%)$ & $14(30 \%)$ \\
\hline
\end{tabular}

n number, RMRP RNA component of mitochondrial RNA processing endoribonuclease, RTL relative telomere length.

We were able to find from the control group age- and sex-matched controls with no $R M R P$ mutations for 40 patients (12 males, 28 females, median age 37.5 years) for case-control analyses. RTL was significantly shorter in patients (median RTL 1.05) compared with the controls (median RTL 1.21, p=0.017). Children aged $\leq 18$ years accounted for this difference in RTL (median 1.09 in patients $v s 1.25$ in controls, $\mathrm{p}=0.015, \mathrm{n}=8$ pairs), while only a trend for shorter RTL was observed in those aged $>18$ and $\leq 40$ years (median 1.07 vs 1.26 in controls, $\mathrm{p}=0.069, \mathrm{n}=14$ pairs) and no difference was detected in the age group $>40$ years (median RTL 1.03 vs 1.08 in controls, $\mathrm{p}=0.443, \mathrm{n}=18$ pairs) (Figure 2).

When all study samples were included in analyses, a significant difference in RTL between patients with $\mathrm{CHH}$ and healthy subjects (including RMRP mutation carriers and non-carriers) was also observed in children (6.0-18.0 years of age, median RTL 1.12 in nine patients $v s 1.26$ in 36 controls, $\mathrm{p}=0.008$ ) (Figure 3). 
220 No significant difference was detected in the older age-groups, although young adults with $\mathrm{CHH}$

221 demonstrated a tendency for shorter telomeres (median RTL 1.08 in 17 patients $v s 1.22$ in 52 controls, $222 \mathrm{p}=0.082)$.

223 We compared RTL in 48 RMRP mutation carriers with age- and sex-matched non-carrier controls, 224 and observed no difference in the median RTL between these two groups (1.16 vs 1.10, $\mathrm{p}=0.224)$ (data not 225 shown).

RTL and CHH-related characteristics and morbidity. In the patient cohort, RTL and classified 227 RTL (short, average or long for age) showed no correlation with the type of RMRP mutation, sex, history of 228 blood transfusions, immunoglobulin substitution, hormone or immunosuppressive therapy, obesity or history 229 of smoking. Various infectious manifestations separately or in combinations, fibrosis-like lung changes, 230 history of malignancies, the severity of growth failure and analyzed laboratory parameters did not correlate 231 with RTL itself or RTL category (Supplementary Table 1). In two patients who had survived lymphoma, RTL 232 was average and long for age respectively. 


\section{DISCUSSION}

Our study demonstrates shorter telomeres in DNA from peripheral blood in children with CHH. The interpretation of our findings necessitates further studies to determine whether shorter telomeres are the cause or the consequence in $\mathrm{CHH}$ pathology. Decreased telomere length may reflect the increased number of cell divisions required to compensate for the impaired cell cycle and increased apoptosis reported in $\mathrm{CHH}$ [18]. Alternatively, telomerase defects can represent primary pathologic mechanism contributing to stem cell exhaustion, including bone marrow failure present in some patients with $\mathrm{CHH}$. Our findings confirm the significance of $R M R P$ in telomerase function.

RTL correlated significantly with age in $R M R P$ mutation carriers and non-carriers, but not in patients with $\mathrm{CHH}$, which can be explained by shorter telomeres in pediatric patients. Individuals with $\mathrm{CHH}$ have increased mortality in childhood and young adulthood from infections and malignancies $[19,20]$. A high proportion of our patients $(46 \%, 22 / 48)$ were over 40 years of age and thus represent a selected population of less affected patients who escaped fatal complications in early life. Therefore, normal telomere length in adults with $\mathrm{CHH}$ can indicate a survival advantage. The absence of correlations between telomere length and clinical and laboratory characteristics can derive from the small sample size. Also, RTL is a rough estimate of telomere structure and represents only a part of the complex telomere biology.

Interestingly, some DC mutation carriers demonstrate telomere shortening while remaining asymptomatic and inheritance of shorter telomeres probably induces more severe disease in subsequent generations [21]. The finding of normal telomeres in $R M R P$ mutation carriers contradicts the data from families with DC. More research is needed to test pedigrees where $\mathrm{CHH}$ has been diagnosed in more than one generation. If the shorter telomere length is indeed inherited, this may result in more severe disease in the affected offspring of patients with $\mathrm{CHH}$ in future generations.

Cell immortalization and subsequent development of cancer can emerge from abnormal telomere maintenance [22]. While DC and $\mathrm{CHH}$ are both characterized by increased risk of malignancies, the types of tumors developing in patients with these disorders differ. The most common malignancies in individuals with DC include head and neck squamous cell carcinomas, while in subjects with $\mathrm{CHH}$, non-Hodgkin lymphomas and basal cell carcinomas predominate [20,23]. Accordingly, in the light of present data, immunodeficiency 
rather than the telomere length is the nominator in predisposition to malignancy in $\mathrm{CHH}$ patients.

Immunodeficiency in patients with $\mathrm{CHH}$ may predispose them to EBV-associated lymphoproliferative disorders. Unfortunately, no data were available on EBV status in lymphoma samples from the two patients in our cohort. The majority of our patients had detectable serum antibodies to EBV but EBV DNA was not detected by PCR in peripheral blood. EBV causes telomere dysfunction in the infected cells [24, 25] and it is possible that this is relevant in $\mathrm{CHH}$. Therefore, further research on alteration in telomere functions and the role of EBV in CHH patients with malignancies would be warranted. hematopoietic stem cell transplantation and defective telomere biology should be taken into account when choosing conditioning regimen. Also, bone marrow failure in patients with DC has been successfully treated with androgens (probably due to telomerase up-regulation) and this treatment option may be considered in selected patients with $\mathrm{CHH}$ [26-28]. Furthermore, telomere length measurement may guide diagnostic process in individuals with immunodeficiency of unknown etiology and $\mathrm{CHH}$ should be included in the differential diagnosis of children with short telomeres.

We recognize strengths and limitations in our study. This is the first study to evaluate telomere length critically short individual telomere ends cannot be detected by this method. in patients with $\mathrm{CHH}$. The high prevalence of the disease in our population provided us with a unique opportunity to recruit a large cohort of patients and their unaffected relatives with a homogenous genetic and ethnic background and with a wide age range; in rare diseases such an approach is seldom possible. The drawbacks of our study include insufficient clinical data from relatives of patients with $\mathrm{CHH}$ and healthy controls. Thus, it was impossible to analyze the influence of e.g. smoking or medications on RTL. However, in the patient group, these factors did not affect telomere length and none of the patients aged $<18$ years reported smoking. The number of healthy controls was rather small, which increases the risk of bias and due to the inter-individual variability of telomere length our data may not be applicable to particular individuals with $\mathrm{CHH}$. Also, no data were available on metabolic profile (glucose, insulin and lipid profile, blood pressure) of our patients, hindering the evaluation of its relationship with RTL. Another limitation is the use of RTL, where mean telomere length of all chromosome ends is estimated. Telomere length distributions and

Our results suggest that telomere length is abnormal in children with $\mathrm{CHH}$. Further studies are required to explore functional consequences of altered telomere maintenance and possible clinical 
290 implications of these findings. Longitudinal follow-up of patients with $\mathrm{CHH}$ is necessary to establish the 291 significance of telomere length as a predictor of disease severity and mortality.

292 


\section{CONTRIBUTORSHIPSTATEMENT}

294

295 Study design: PK, MT, GR and OM. Study conduct: SK, MP, SD. Data collection: SK. Data analysis: SK,

296 SD, ML. Data interpretation: SK, SD, MT, GR, OM. Drafting manuscript: SK. Revising manuscript content:

297 All authors. Approving final version of manuscript: All authors. 


\section{FUNDING}

299

300 This work was supported by the Sigrid Jusélius Foundation [to OM]; the Academy of Finland [to OM]; the

301 Folkhälsan Research Foundation [to OM]; the Helsinki University Hospital Research Funds [to OM and

302 MT]; the Foundation for Pediatric Research [to OM and MT]; the Swedish Childhood Cancer Foundation [to

303 OM and SD]; the Lion's cancer foundation in Umeå [to SD and GR]; the Doctoral School in Health Sciences

304 at the University of Helsinki [to SK]; the Swedish Cancer Research Foundation [to GR]; and the

305 Västerbotten County Council [to GR and SD]. 


\section{COMPETING INTERESTS}

307

308 The authors declare no conflicts of interest. 


\section{ACKNOWLEDGEMENTS}

310

311 The authors would like to thank laboratory assistants Hanna Hellgren, Maura Kere and Natalia Kakko for

312 their help in performing DNA extraction and $R M R P$ sequencing, and Susann Haraldsson for telomere length

313 measurements.

314 


\section{CONFLICT OF INTEREST STATEMENT}

316

317 The authors declare no conflicts of interest. 


\section{REFERENCES}

1 Blackburn EH, Epel ES, Lin J. Human telomere biology: A contributory and interactive factor in aging, disease risks, and protection. Science 2015;350,1193-8.

2 Low KC, Tergaonkar V. Telomerase: central regulator of all of the hallmarks of cancer. Trends Biochem Sci $2013 ; 38,426-34$.

3 Ridanpää M, van Eenennaam H, Pelin K, Chadwick R, Johnson C, Yuan B, vanVenrooij W, Pruijn G,

Salmela R, Rockas S, Mäkitie O, Kaitila I, de la Chapelle A. Mutations in the RNA component of RNase

MRP cause a pleiotropic human disease, cartilage-hair hypoplasia. Cell 2001;104,195-203.

4 McKusick VA, Eldridge R, Hostetler JA, Ruangwit U, Egeland JA. Dwarfism in the Amish: II. Cartilagehair hypoplasia. Bull Johns Hopkins Hosp 1965;116,285-326.

5 Mäkitie O. Cartilage-hair hypoplasia in Finland: epidemiological and genetic aspects of 107 patients. $J$

6 Mäkitie O, Kaitila I. Cartilage-hair hypoplasia--clinical manifestations in 108 Finnish patients. Eur J Pediatr 1993;152,211-7.

3397 Mäkitie O, Pukkala E, Teppo L, Kaitila I. Increased incidence of cancer in patients with cartilage-hair 340 hypoplasia. J Pediatr 1999;134,315-8.

3428 Thiel CT, Mortier G, Kaitila I, Reis A, Rauch A. Type and level of RMRP functional impairment predicts 343 phenotype in the cartilage hair hypoplasia-anauxetic dysplasia spectrum. Am J Hum Genet 2007;81,519-29. 
LD, Giliani S, Bouhassira E, Frenette P, Roy-Chowdhury J, Rogler CE. Small RNAs derived from lncRNA

RNase MRP have gene-silencing activity relevant to human cartilage-hair hypoplasia. Hum Mol Genet $2014 ; 23,368-82$.

10 Maida Y, Yasukawa M, Furuuchi M, Lassmann T, Possemato R, Okamoto N, Kasim V, Hayashizaki Y,

Hahn WC, Masutomi K. An RNA-dependent RNA polymerase formed by TERT and the RMRP RNA.

Nature 2009;461,230-5.

11 Savage SA. Dyskeratosis Congenita. In: Pagon RA, Adam MP, Ardinger HH, Wallace SE, Amemiya A,

Bean LJH, Bird TD, Fong CT, Mefford HC, Smith RJH, Stephens K. (eds). SourceGeneReviews® [Internet].

12 Armanios MY, Chen JJ, Cogan JD, Alder JK, Ingersoll RG, Markin C, Lawson WE, Xie M, Vulto I,

Phillips JA. 3rd, Lansdorp PM, Greider CW, Loyd JE. Telomerase mutations in families with idiopathic pulmonary fibrosis. N Engl J Med 2007;356,1317-26.

13 Kostjukovits S, Klemetti P, Föhr A, Kajosaari M, Valta H, Taskinen M, Toiviainen-Salo S, Mäkitie O.

High prevalence of bronchiectasis in patients with cartilage-hair hypoplasia. J Allergy Clin Immunol (in press).

14 Mäkitie O, Perheentupa J, Kaitila I. Growth in cartilage-hair hypoplasia. Pediatr Res 1992;31,176-80.

15 Mäkitie O, Kaitila I, Savilahti E. Susceptibility to infections and in vitro immune functions in cartilage-

hair hypoplasia. Eur J Pediatr 1998;157,816-20.

16 Cawthon RM. Telomere measurement by quantitative PCR. Nucleic Acids Res 2002;30,e47. 
parkinsonism. PLoS One 2014;9,e113387.

18 de la Fuente MA, Recher M, Rider NL, Strauss KA, Morton DH, Adair M, Bonilla FA, Ochs HD, Gelfand EW, Pessach IM, Walter JE, King A, Giliani S, Pai SY, Notarangelo LD. Reduced thymic output, cell cycle abnormalities, and increased apoptosis of T lymphocytes in patients with cartilage-hair hypoplasia. $J$ Allergy Clin Immunol 2011;128,139-46.

19 Mäkitie O, Pukkala E, Kaitila I. Increased mortality in cartilage-hair hypoplasia. Arch Dis Child $2001 ; 84,65-7$.

20 Taskinen M, Ranki A, Pukkala E, Jeskanen L, Kaitila I, Mäkitie O. Extended follow-up of the Finnish cartilage-hair hypoplasia cohort confirms high incidence of non-Hodgkin lymphoma and basal cell carcinoma. Am J Med Genet A 2008;146A,2370-5.

21 Vulliamy T, Marrone A, Szydlo R, Walne A, Mason PJ, Dokal I. Disease anticipation is associated with progressive telomere shortening in families with dyskeratosis congenita due to mutations in TERC. Nat Genet 2004;36,447-9.

22 Kim NW, Piatyszek MA, Prowse KR, Harley CB, West MD, Ho PL, Coviello GM, Wright WE, Weinrich SL, Shay JW. Specific association of human telomerase activity with immortal cells and cancer. Science $1994 ; 266,2011-5$.

23 Alter BP, Giri N, Savage SA, Rosenberg PS. Cancer in dyskeratosis congenita. Blood 2009;113,6549-57.

24 Ding L, Li LL, Yang J, Tao YG, Ye M, Shi Y, Tang M, Yi W, Li XL, Gong JP, Cao Y. Epstein-Barr virus 400 encoded latent membrane protein 1 modulates nuclear translocation of telomerase reverse transcriptase 401 protein by activating nuclear factor-kappaB p65 in human nasopharyngeal carcinoma cells. Int J Biochem 
40425 Kamranvar SA, Chen X, Masucci MG. Telomere dysfunction and activation of alternative lengthening of 405 telomeres in B-lymphocytes infected by Epstein-Barr virus. Oncogene. 2013;5;32:5522-30.

406

40726 Khincha PP, Wentzensen IM, Giri N, Alter BP, Savage SA. Response to androgen therapy in patients with 408 dyskeratosis congenita. Br J Haematol 2014;165,349-57.

409

41027 Bär C, Huber N, Beier F, Blasco MA. Therapeutic effect of androgen therapy in a mouse model of 411 aplastic anemia produced by short telomeres. Haematologica 2015;100,1267-74.

412

41328 Townsley DM, Dumitriu B, Liu D, Biancotto A, Weinstein B, Chen C, Hardy N, Mihalek AD, Lingala S, 414 Kim YJ, Yao J, Jones E, Gochuico BR, Heller T, Wu CO, Calado RT, Scheinberg P, Young NS. Danazol 415 Treatment for Telomere Diseases. N Engl J Med 2016;374,1922-31. 


\section{LEGENDS TO FIGURES}

419 Figure 1. Correlation of relative telomere length with age in 228 samples from patients with cartilage-hair hypoplasia, their relatives and healthy controls. Every dot corresponds to a measurement from a single individual. RTL correlated significantly with age in $R M R P$ mutation carriers (rho $-0.482, \mathrm{p}<0.001$ ) and noncarriers (rho $-0.498, \mathrm{p}<0.001$ ), but not in patients (rho $-0.236, \mathrm{p}=0.107$ ).

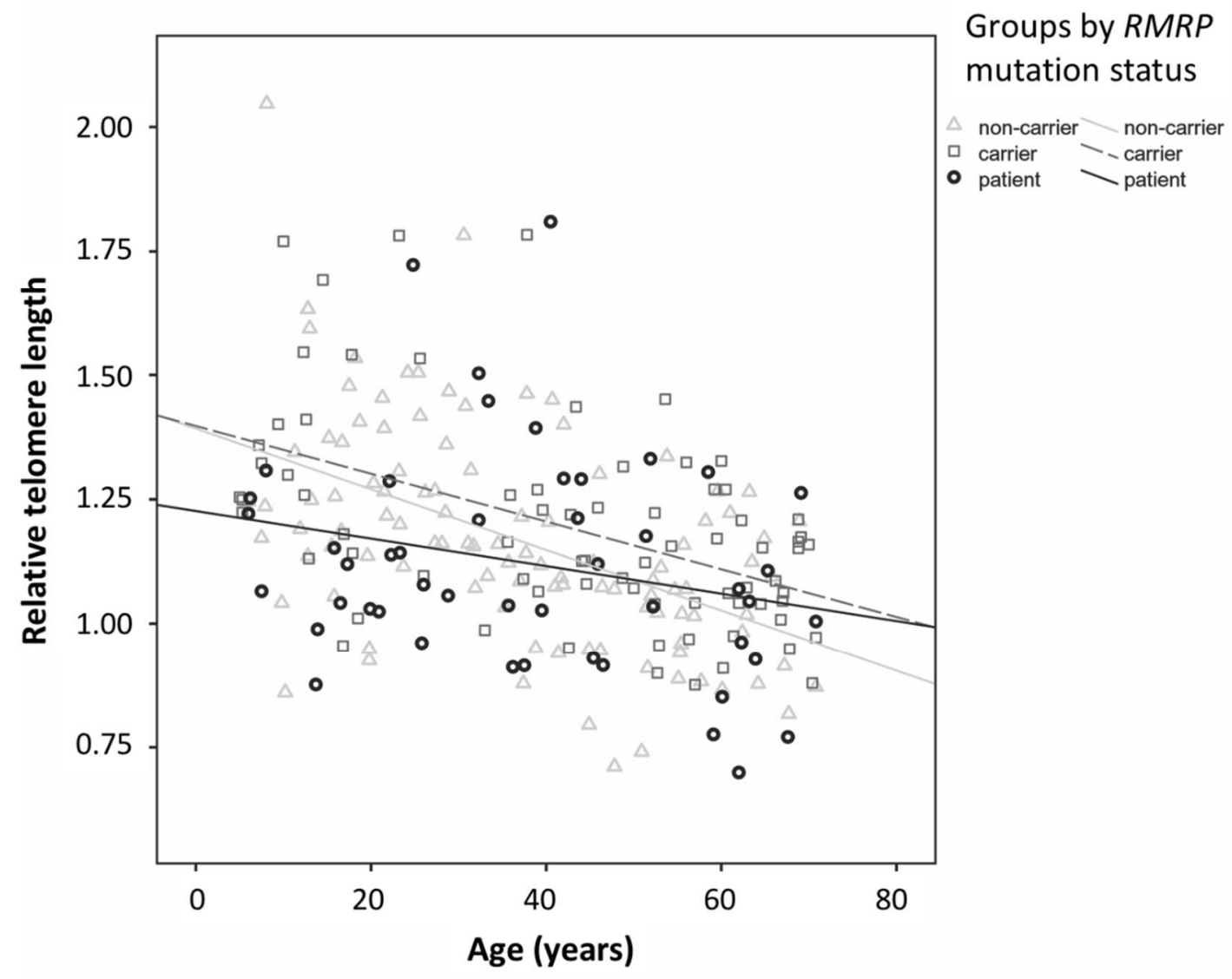

Figure 2. Comparison of relative telomere length (RTL) in a case-control setting in 40 patients with cartilage-hair hypoplasia (median RTL 1.05) and 40 age- and gender-matched healthy controls negative for RMRP mutation (median RTL 1.21, $\mathrm{p}=0.017$ ). RTL was significantly shorter in children with CHH (median 1.09 vs 1.25 in controls, $\mathrm{p}=0.015, \mathrm{n}=8$ pairs). Adults with $\mathrm{CHH}$ showed a trend for shorter RTL in the age group $>18$ and $\leq 40$ years (median 1.07 vs 1.26 in controls, $\mathrm{p}=0.069, \mathrm{n}=14$ pairs), while no difference was detected in the age group $>40$ years (median RTL 1.03 vs 1.08 in controls, $\mathrm{p}=0.443, \mathrm{n}=18$ pairs). 


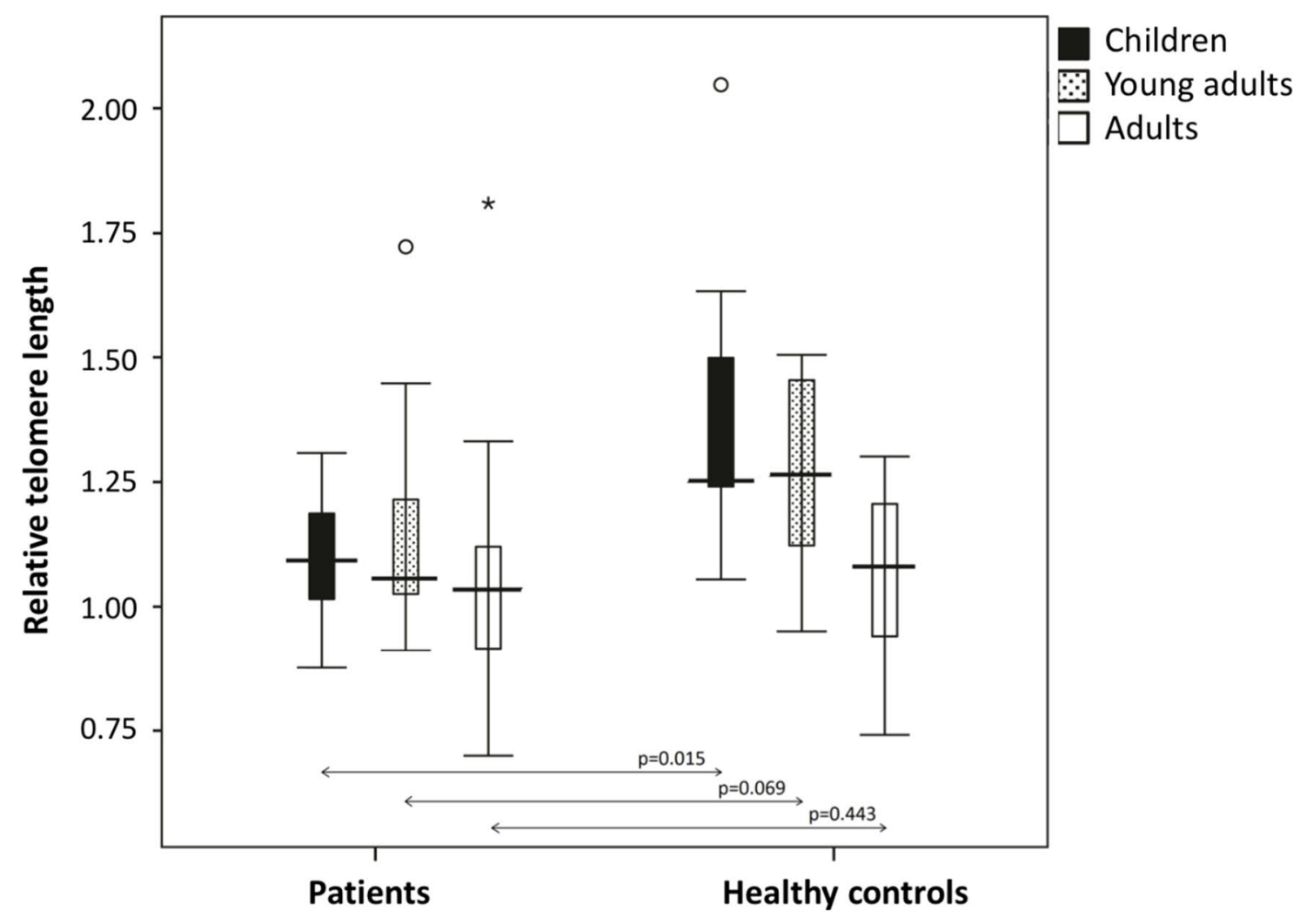

431

432

433 Figure 3. Comparison of relative telomere length (RTL) in different age groups of patients with cartilage-hair 434 hypoplasia (CHH), RMRP mutation carriers and non-carriers. Children with $\mathrm{CHH}$ (aged $\leq 18$ years)

435 demonstrate significantly shorter RTL compared with asymptomatic mutation carriers and non-carriers. No

436 difference in RTL was observed in young adults (aged $>18$ and $\leq 40$ years) or adults (aged $>40$ years) with

437 CHH compared with controls. 


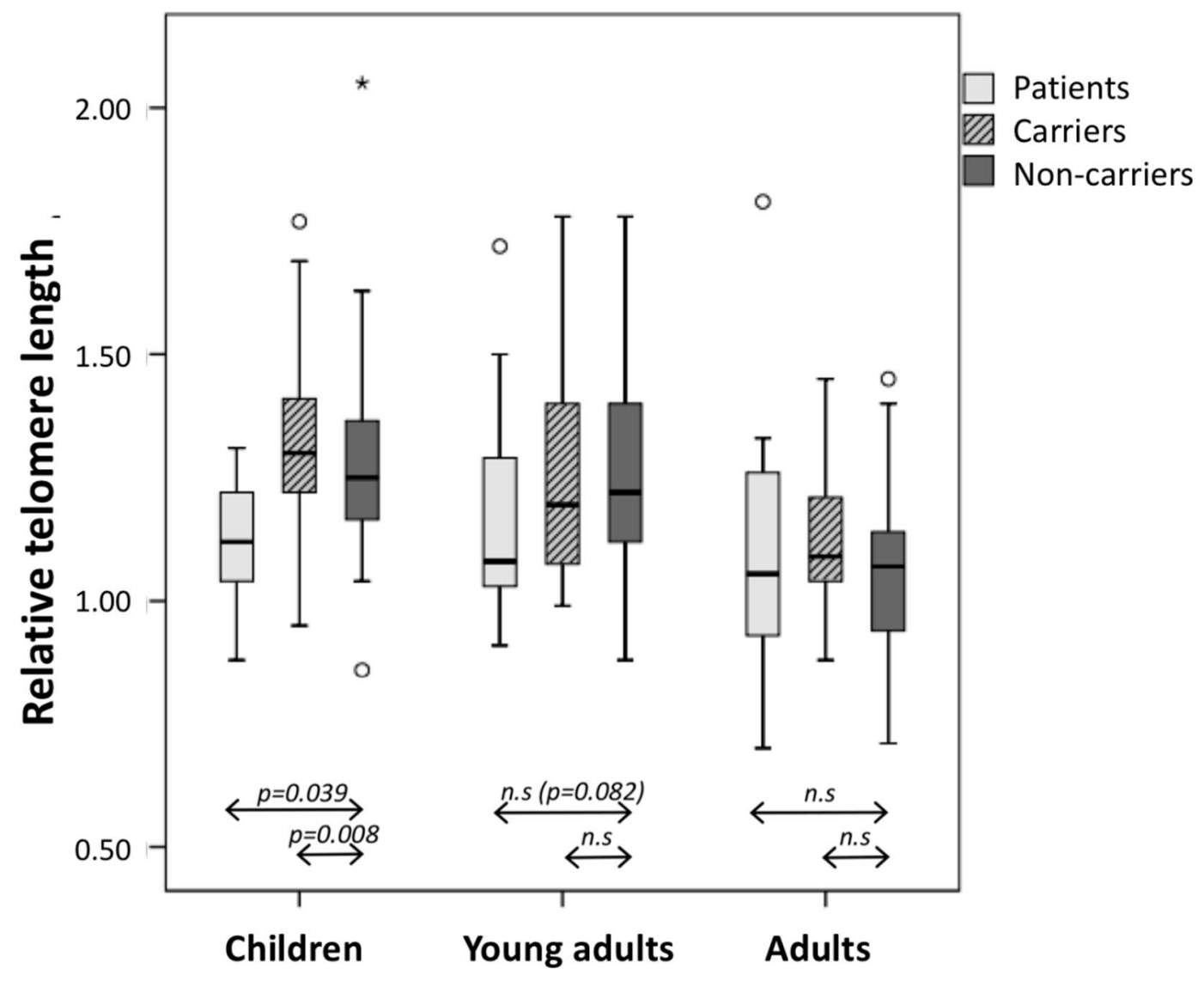

438

439 


\section{ABBREVIATIONS}

441

$442 \mathrm{CHH}$, cartilage-hair hypoplasia

443 DC, dyskeratosis congenita

444 EBV Epstein-Barr virus

445 rho, Spearman's correlation coefficient

$446 R M R P$, RNA component of mitochondrial RNA processing endoribonuclease

447 RTL, relative telomere length

448 SD standard deviation

449 TERT, telomerase reverse transcriptase 